\title{
UMA BREVE REFLEXÃO ACERCA DA INSTITUIÇÃO FAMÍLIA COMO ANTECEDENTE ESPISTEMOLÓGICO DE INVESTIGAÇÕES EM ORGANIZAÇÕES FAMILIARES
}

\author{
A BRIEF REFLECTION ON THE FAMILY INSTITUTION AS AN \\ EPISTEMOLOGICAL BACKGROUND OF FAMILIES \\ ORGANIZATIONS RESEARCHES
}

Claudio Eduardo Ramos Camfield ${ }^{1}$

Recebido em: 07/01/2016

Aprovado em: 26/10/2016

\section{RESUMO}

Este trabalho tem como objetivo fazer uma reflexão epistemológica sobre a instituição família e a sua representação. Trata-se de um estudo sobre as representações que se têm de família e, por conseguinte, sobre os valores e outros aspectos culturais que formam a identidade familiar entre as gerações. Como esta pesquisa desenvolvida é de caráter descritivo, utilizou-se bibliografia prévia que denotasse os termos ora pretendidos e que concedesse uma sustentação aos argumentos e ao objetivo do estudo. Evidenciou-se que existem algumas formações de como se constitui a imagem ou a identidade da instituição família. Foi perceptível, ainda, que essa instituição passou por muitas mutações, sendo afetada no decorrer do tempo por vários fatores advindos do crescimento e do desenvolvimento das nações, dos povos ou da sociedade como um todo.

Palavras-chave: Família, Instituição Família, Identidade Familiar, Representação de Família, Empresa Familiar.

\begin{abstract}
This paper has as his objective an epistemological reflection on the family institution and its representation. It is a study about the representations one has of family and, therefore, about the values and concepts that form a family identity between the generations. As this research was developed with a descriptive aproach, a previous bibliography was used that denoted the terms that were intended and that allowed a support to the arguments and the objective of the study. It has been shown that there are some forms of how are constituted an image or an identity of the family institution. It was also seen that the family institution has changed many times in history, and has been afected by several factors influenced by the growth and development of nations.

Keywords: Family, institution of the family, Family Identity, Family Representation, Family Firms.
\end{abstract}




\section{Introdução}

As últimas décadas têm sido marcadas por um aumento significativo de pesquisas e de avanços teóricos sobre o fenômeno "empresas familiares", delimitando um campo específico de estudo, o que não excluiu contribuições fecundas para o desenvolvimento de uma teoria administrativa e organizacional mais abrangente (DAVEL, 2003). O autor infere, ainda, que existe um incremento dos trabalhos empíricos focados no estudo das organizações familiares sob uma perspectiva sociocultural, a qual incorpora métodos e teorias assimilados de outros campos das ciências sociais e humanas.

Davel \& Colbari (2000) destacam que os aspectos qualitativos da esfera familiar nas organizações têm sido aprofundados por muitos investigadores da administração e das ciências sociais, englobando dimensões materiais e imateriais. Nesse aspecto, os autores reverberam que, sob um prisma predominantemente pragmático, estrutural e funcionalista, o campo teórico específico dos estudos sobre empresas familiares irá empreender pesquisas mais voltadas para as questões imateriais, como sucessão, ciclo de vida, profissionalização, estratégia etc. Entretanto, recentemente, os estudiosos em ciências sociais têm mostrado interesse e desenvolvido pesquisas sobre os aspectos simbólicos e culturais da vida organizacional, relacionando-os às imagens do universo familiar.

Levando em consideração essas argumentações, verifica-se que, em se tratando de investigações sobre empresas familiares, torna-se importante uma abordagem subjetiva no momento de entender esse tipo de organização, pois a empresa familiar é complexa, podendo ser vista como um conjunto de sistemas que compõe a priori três instituições, ou seja, a família, a propriedade e a gestão (GERSICK et al., 2006). Nesse sentido, nuances são geradas em cada uma dessas instituições, devido a características específicas, advindas prioritariamente de fatores culturais da própria família, como valores, crenças, ideologias, imagens e símbolos.

Cabe ressaltar, assim, a importância desse tipo de estudo, que busca um rol de significados epistemológicos que contribuam para um entendimento mais pertinente sobre questões antecedentes e que estimulem o desenvolvimento de outros estudos a posteriori sobre diversas temáticas que envolvam as empresas familiares. Destarte, este trabalho tem por objetivo fazer uma reflexão epistemológica sobre a instituição família e a sua representação, partindo-se do princípio de que essa instituição é o cerne subjacente e interveniente no modelo sistêmico composto das três instituições supracitadas. Com base no exposto, este estudo trata das representações de família, bem como discute os valores e outros aspectos culturais que formam a identidade familiar entre as gerações.

\section{Família}

As representações familiares partem de uma concepção de família como sendo algo contruído codidiana e discursivamente. Portanto, a família diz respeito à forma de interpretar, de representar e de organizar as relações sociais, produzindo um modo de criar sentido para tais relações (GUBRIUM \& HOLSTEIN, 1990; HOLSTEIN \& GUBRIUM, 1994).

Para Holstein \& Gubrium (1994), a família pode ser entendida como imagem, conceito, recurso ou metáfora, podendo ser mobilizada para se responder a desafios interpretativos, ligados ao status e ao significado dos laços sociais. Oo significado familiar pode, por exemplo, desempenhar um aspecto prático quando a qualidade ou profundidade da relação social de alguém é questionada. Pode, também, desempenhar papel político ou psicossocial quando a organização é concebida como representação 
do lar ou da mãe protetora (PAGÈS, BONETTI, GAULEJAC \& DESCENDRE, 1979; BROWN \& MCCARTNEY, 1996; CASEY, 1999; GABRIEL, 1999; KONDO, 2009).

Sob essa perspectiva, para fins deste estudo, trabalhou-se a dimensão da família tendo por base alguns conceitos e tipologias, sempre com o intuito de demonstrar que a família não é algo estático, mas que continua passando por mudanças e desdobramentos estruturais e afetivos. Nesse sentido, um dos primeiros conceitos que cabe apresentar advém do dicionário de Sociologia Globo (1967), que define a família como uma instituição social básica, que compreende um ou mais homens vivendo maritalmente com uma ou mais mulheres e que pode ser ou ter descendentes e, às vezes, outros parentes agregados, gerando, assim, em torno desse núcleo, uma organização que assume as feições mais variadas. Essa definição indica uma concepção tradicional (patriarcal) do termo família, em que se tem a figura representativa de pais e filhos ou, em um sentido mais abrangente, a inclusão de parentes próximos, o que pode ser descrito, de acordo com a literatura, como a família nuclear ou família extensiva.

Diante de tantas concepções geradas no decorrer da história de família patriarcal, Freire (1981) define-a como sendo aquela com as seguintes características: sistema hierárquico, autoridade paterna prevalecente, monogamia e indissolubilidade do casamento. Entretanto, a compreensão da instituição família veio sofrendo mutações no decorrer do tempo, principalmente nos países ocidentais. Tais alterações ocorreram principalmente pela existência de alguns fatos, tais como a presença de novas tecnologias, o movimento feminista e, com isso, o aumento da inserção da mulher no mercado de trabalho, assim como das dissoluções matrimoniais. Castells (1999) também entende que as mudanças ocorridas na institui- ção família foram advindas da inserção das mulheres no mercado de trabalho, da globalização e das transformações tecnológicas, proporcionando impactos na esfera do trabalho e na eliminação de qualquer forma de opressão ou desigualdade de poder.

Indo ao encontro das mutações conceituais das representações da intituição família, principalmente no que tange à decadência do modelo de família patriarcal, Castells (1999, p. 169) acrescenta que a principal transformação que está ocorrendo na família é o fim do patriarcalismo, "caracterizado pela autoridade, imposta institucionalmente, do homem sobre mulher e filhos no âmbito familiar". Nessa mesma linha de pensamento, Dias \& Lopes (2003) afirmam que com o enfraquacimento da família instituída no modelo patriarcal é oriundo de uma concepção de família mais igualitária, sendo os seus membros percebidos como iguais, com direitos similares, embora diferenças sexuais e etárias se encontrem presentes.

Também cabe ressaltar que essas mudanças levam, cada vez mais, à dissolução dos casamentos que originaram a família tradicional, como estavam acostumadas as gerações passadas, levando à formação de lares de solteiros ou lares com apenas um dos pais, o que corrobora com o argumento da decadência da autoridade patriarcal sobre a família. Sob esse aspecto, Gomes \& Paiva (2003) referem-se a uma nova configuração do conceito de casamento surgida a partir do século XXI, mencionando que, uma vez que as famílias vão se constituindo de forma mais ampla, incluindo novos parceiros, filhos e irmãos agregados, o pai perde substancialmente sua tradicional função, concedendo espaço à figura maternal.

Ainda com relação às modificações do matrimônio na formação da instituição família, Castells (1999) acrescenta que o adiamento da formação de casais, derivado da dificuldade de compatibilizar casamento, trabalho 
e vida, bem como a formação de relacionamentos sem casamento legalizado, contribui para enfraquecer a autoridade patriarcal tanto institucional quanto psicologicamente. $\mathrm{O}$ autor menciona, ainda, que esse contexto de transformações é acompanhado de novas formas de pensar a vida familiar, incluindo as famílias gays. À medida que esses valores foram sendo incorporados à vida conjugal, as relações tornaram-se abertas à negociação, permitindo a legitimação de formas familiares outrora não aceitas socialmente, como, por exemplo, a de parceiros do mesmo sexo.

Outro aspecto importante para essa transormação da família é o aumento do número de crianças nascidas fora do casamento, fator que estabeleceu uma desconexão entre elementos que historicamente eram interligados: casal, casamento e família (FONSECA, 2004). Destarte, a autora argumenta que não há um modelo homogêneo e hegemônico quando se busca compreender as formas familiares predominantes na sociedade atual. $\mathrm{O}$ modelo atual é uma extensão do ideal de família preconizado na modernidade, que enfatiza o amor romântico, o matrimônio ideal e o afeto como base da vida familiar.

Diante do contexto apresentado, Castells (1999) conclui que essas tendências indicam o fim da família nuclear sob o domínio patriarcal, como foi conhecida há milênios. Corroborando esse pensamento, Todd (1985) infere que o conceito de família está inserido em um sistema ideológico mais amplo, ao mesmo tempo que desenvolve e reproduz um sistema de valores próprios.

Nesse sentido, Davel \& Dantas (2004) apresentam uma possível classificação contemporânea das famílias por grupos:

- Família consanguínea nuclear;

- Família consanguínea normal (a do modelo antigo, com oito filhos ou mais);

- Família consanguínea reduzida (a atual família, com, muitas vezes, apenas um filho);

- Família consanguínea múltipla (família formada por casais separados, que têm filhos nos seus primeiros casamentos e, muitas vezes, nos casamentos subsequentes);

- Família consanguínea descontínua (avós que criam filhos de pais falecidos ou de adolescentes);

- Família consanguínea dispersa (filhos fora dos casamentos);

- Família legal (filhos adotados que vêm formar uma família nuclear);

- Família emergente (casais homossexuais com filhos de casamentos heterossexuais anteriores);

- Família emergente de adoção (casais homossexuais com filhos adotados);

Tendo em vista os aspectos socioculturais, há, ainda, outros conceitos de famílias, tais como:

- Famílias étnicas (considerar-se irmãos por pertencer a uma mesma etnia);

- Famílias por consideração (padrinhos e afilhados);

- Famílias religiosas;

- Família cristã (filhos de Deus, todos irmãos etc.);

- Família de santo (presente principalmente no contexto baiano, Candomblé);

- Outras famílias religiosas.

Tendo a família nuclear como ponto central, Banfield (1958), em The moral basis of a backward society, descreve a constituição, a prática e os limites deste ethos familista, tratando, mais precisamente, do "familismo amoral". Quando o autor realizou sua investigação em Montegrano, uma cidade do sul da Itália, durante a década de 50, ficou impressionado com a forma pela qual os habitantes se limitavam ao âmbito de suas famílias nucleares. Ele criou, então, a expressão "familismo amoral" para dar conta de uma situação em que a solidariedade social e o sentimento de pertencimento não se prolongavam fora do ambiente da família - familismo amoral designava um ethos 
que excluía a colaboração fora do círculo restrito da família.

Banfield (1958) observou, assim, que o cerne familiar são os pais e os filhos, sendo os avós, tios e primos excluídos da família. Nesse sentido, na concepção do autor, a proteção da criança é provida unicamente pelos pais, de modo que, na falta destes, a criança está condenada às ruas, pois não existem em Montegrano instituições que extrapolem o âmbito familiar. Essa forma de viver e de construção familiar foi descrita pelo autor como sendo a expressão cultural, psicológica e moral da combinação de uma série de condições peculiares à região, que vão desde sua estagnação econômica à estrutura familiar.

Se, por um lado, o declínio da família extensa contribuiu decisivamente para o declínio dos laços de solidariedade social, por outro, a circunscrição dos limites da família ao seu núcleo central, aliada aos fatores de instabilidade e ao temor quanto ao futuro característico daquela sociedade, contribuíram para fortalecer a família nuclear, tornando-a a unidade social por excelência. Devese perceber, portanto, que o declínio da família extensa não deu origem ao tipo de individualismo característico das sociedades modernas: "um adulto não possui identidade fora da esfera da família; não existe enquanto ego, apenas como parcela" (BANFIELD, 1958, p. 103).

Ressalta-se que não cabe neste estudo realizar toda a descrição da investigação de Banfield, mas apenas levantar mais um questionamento sobre as formas de família existentes, mais precisamente a nuclear, a qual, segundo a literatura, é a principal base para as construções de outras formas de família. Além disso, o estudo de Banfield convida para uma reflexão perante uma realidade por ele encontrada que pode ter influenciado os traços de outras sociedades modernas.

Dentre todas essas classificações, existe um direcionamento para a afeti- vidade, apresentada por muitos autores como os laços afetivos que vão além dos laços de sangue, como cita Sawaia (2000, p. 5): "a afetividade é uma dimensão fundamental da atividade transformadora e [...] é questão importante na análise dos problemas sociais" e, portanto, das relações familiares.

Todos os argumentos referentes à origem e às tipologias da família até aqui apresentados têm caráter informativo, pois se reconhece que o modelo de família patriarcal inserido na cultura ocidental, via catolicismo, não é único. Entretanto, sua preponderância em número e sua influência em termos de valores éticos e morais em todos os outros tipos de famílias apresentadas ainda se fazem demasiadamente homogeneizadoras.

\section{Valores e outros aspectos culturais formadores da identidade familiar transgeracional}

Por mais variada que for a utilização da ideia e do conceito de família, conforme os argumentos e as conceituações elencadas na seção anterior, tornase importante ressaltar que os valores construídos na família nuclear ou fora dela (família extensiva) são fundamentais para a construção das identidades morais, éticas, culturais etc. Esse argumento é corroborado por Velho (1987), que infere que a articulação da família é significativa para a construção social da identidade e, portanto, fundamental para a compreensão da subjetividade dos indivíduos que compõem uma sociedade.

Diante disso, Falcke \& Wagner (2005) utilizam o termo transgeracional para explicar os fenômenos que ocorrem no âmbito familiar e que formam as identidades das famílias. Nesse sentido, a seguir, discute-se cada um dos fenômenos, que na literatura diversa, também são vistos como componentes de uma cultura, neste caso, familiar.

Um dos fenômenos que compõem a identidade familiar consisite nos valores pessoais e/ou sociais. Quando 
se fala em valores, ressalta-se que estes não são propriedade dos objetos em si, mas atingem propriedade graças à sua relação com o homem, enquanto sujeito social. Apesar do fato que os objetos também têm um valor em função de certas propriedades objetivas, é o homem como ser histórico-social e a sua atividade prática que criam os valores e os bens nos quais acreditam e seguem. Os valores são, portanto, criações humanas e só existem e se realizam no homem e pelo homem (VÁZQUEZ, 2001).

Quanto ao campo da família, Falcke \& Wagner (2005) argumentam que os valores familiares comumente são definidos como sinônimos de crenças familiares. De Oliveira Cerveny \& Berthoud (1997), entretanto, entendem que valores familiares são os aspectos da vida - individual e coletiva - transmitidos, implicita ou explicitamente, entre os componentes do sistema. Neles estão inseridos os segredos, os tabus, os mitos, as crenças, os rituais e as cerimônias realizadas pela família que correspondem à ideologia do sistema familiar.

A lealdade também é um dos fenômenos importantes para o conjunto que compõe a identidade familiar. De acordo com Falcke \& Wagner (2005), o conceito de lealdade é fundamental para compreender a estrutura relacional mais profunda das famílias e de outros grupos sociais, podendo ser definida como moral, política e psicológica. Nesse sentido, Paccola (1994 apud FALCKE \& WAGNER (2005) infere que, em suas múltiplas formas de expressão, a lealdade institui uma força saudável ou não que cria vínculos de conexão entre gerações passadas e futuras em uma família.

Compondo o rol dos fenômenos da identidade familiar, há as crenças. Conforme Dallos (1996), o conceito de crença tem sido definido a partir de aspectos religiosos, morais, cognitivos e pessoais, estando inserido em uma série de interpretações e premissas com relação àquilo que se considera como certo e que, de uma forma ou de outra, define a identidade familiar (FALCKE \& WAGNER, 2005). Corroborado essa conceituação, Steinglass et al. (1989) destacam que a identidade familiar está baseada em uma estrutura cognoscitiva subjacente, isto é, em uma série de crenças, de atitudes e de atribuições fundamentais que a família compartilha a respeito de si mesma.

Os mitos também são importantes para o constructo da identidade familiar. No seu sentido mais amplo, o mito é um sistema explicativo dos mais diferentes fenômenos da vida, buscando fornecer explicações para temas relativos desde a origem do mundo, do homem e da família até as transições do ciclo de vida familiar, como o nascimento, o casamento e a morte (MIERMONT, 1994). Sendo assim, o mito diz respeito a todos os membros do sistema familiar, o que não permite a sua contestação por nenhum destes, apesar de, muitas vezes, os mitos conterem claras distorções da realidade (PINCUS \& DARE, 1981; ANDOLFI \& ANGELO, 1989; MIERMONT, 1994). Por fim, Rios González (1994) afirma que, embora pareçam irracionais e irreais, quando vistos de fora, os mitos familiares são parte integrante da realidade familiar.

Quanto aos segredos, Imber-Black (1994) afirma que são fenômenos sistêmicos que acabam moldando díades, formando triângulos, encobrindo alianças, provocando divisões ou rompimentos $\mathrm{e}$ definindo limites de quem está "dentro" e de quem está "fora". Frente a alguma atitude não aceita pela cultura familiar, os segredos surgem como forma de esconder determinados fatos que não correspondam às exigências estabelecidas pelos padrões familiares, bem como de perpetuar os tabus sagrados que se mantêm entre gerações (IMBER-BLACK, 1994; PRADO, 1996).

Não menos importantes para a composição da identidade familiar são os ritos ou rituais. Na acepção de Falcke \& Wagner (2005), não se observa na literatura uma diferenciação clara entre 
os conceitos de rito e ritual, sendo ambos utilizados por diferentes autores para definir o mesmo fenômeno. No ambiente familiar, os ritos são uma série de atos e de comportamentos estritamente codificados na família, que se repetem no tempo e dos quais participam todos ou uma parte dos familiares (MIERMONT, 1994). Ainda de acordo com o autor, os ritos possuem uma clara função de aprendizagem, pois, por seu intermédio, cada membro da família aprende a conhecer os outros e a comportar-se de modo adequado em relação a eles. Essa ideia é corroborada por Paccola (1994), ao afirmar que os ritos têm a tarefa de transmitir a cada participante da família os valores, as atitudes e as modalidades comportamentais relativas a situações específicas ou a vivências emocionais.

Como último componente da identidade familiar, existem os legados. Conforme Steinglass et al. (1989), o legado de família é uma espécie de cápsula do tempo, em que a família coloca os elementos que, na forma mais condensada, comunicam às gerações futuras a essência da família atual.

Com a finalidade de resumir de forma sistemática os fenômenos transgeracionais citados por Falcke \& Wagner (2005), apresenta-se, a seguir, o Quadro 1.

Quadro 1: Quadro conceitual e diferencial dos fenômenos transgeracionais

\begin{tabular}{|c|c|c|c|}
\hline & CONCEITO & CARACTERÍSTICAS PRINCIPAIS & $\begin{array}{l}\text { AUTORES PRIN- } \\
\text { CIPAIS }\end{array}$ \\
\hline 舜 & $\begin{array}{l}\text { São forças que tornam o sujeito } \\
\text { um membro efetivo do grupo e } \\
\text { lhe exigem, em troca, o compro- } \\
\text { misso de cumprir os mandatos } \\
\text { do sistema. }\end{array}$ & $\begin{array}{l}\text { - Marcam o pertencimento; } \\
\text { - São regidas por um componente de } \\
\text { obrigação ética; } \\
\text { - Visam criar um vínculo de ligação entre } \\
\text { os membros do sistema, inclusive trans- } \\
\text { geracionalmente. }\end{array}$ & $\begin{array}{l}\text { Boszormenyi- } \\
\text { nagy \& Spark } \\
(1973)\end{array}$ \\
\hline 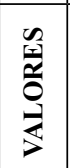 & $\begin{array}{l}\text { São aspectos que a família ou o } \\
\text { grupo se preocupam em trans- } \\
\text { mitir aos seus descendentes. }\end{array}$ & $\begin{array}{l}\text { - Correspondem à ideologia do sistema } \\
\text { familiar; } \\
\text { - Podem ser explílitos ou impícitos. }\end{array}$ & $\begin{array}{l}\text { De Oliveira Cer- } \\
\text { veny \& Berthoud } \\
\text { (1997) }\end{array}$ \\
\hline 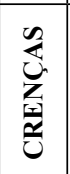 & $\begin{array}{l}\text { Trata-se de um conjunto de pres- } \\
\text { supostos em relação ao que é } \\
\text { certo ou errado e que, em função } \\
\text { disso, deve ser incorporado pela } \\
\text { família ou não. }\end{array}$ & $\begin{array}{l}\text { - Constituem a base da identidade fami- } \\
\text { liar. }\end{array}$ & Dallos (1996) \\
\hline$\stackrel{0}{E}$ & $\begin{array}{l}\text { São sistemas explicativos de } \\
\text { aspectos da vida que, conscien- } \\
\text { temente, são difíceis de serem } \\
\text { compreendidos ou aceitos. }\end{array}$ & $\begin{array}{l}\text { - Têm a finalidade de garantir a coesão } \\
\text { da família; } \\
\text { - Servem para encobrir uma realidade } \\
\text { penosa; } \\
\text { - Têm um componente fortemente in- } \\
\text { consciente. }\end{array}$ & $\begin{array}{l}\text { Ferreira (1963); } \\
\text { Andolfi \& Angelo } \\
\text { (1989); } \\
\text { Ríos Gonzáles } \\
\text { (1994) }\end{array}$ \\
\hline 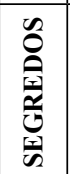 & $\begin{array}{l}\text { Consistem em atitudes de es- } \\
\text { conder fatos ou sentimentos que } \\
\text { não correspondem aos padrões } \\
\text { familiares e sociais ou que dizem } \\
\text { respeito à privacidade do sujeito. }\end{array}$ & $\begin{array}{l}\text { - Violam as regras sobre a posse comum } \\
\text { das afirmações; } \\
\text { - Reforçam os limites e as fronteiras do } \\
\text { sistema. }\end{array}$ & $\begin{array}{c}\text { Imber-Black } \\
\text { (1994) } \\
\text { Carpenter \& } \\
\text { Treacher }(1993)\end{array}$ \\
\hline 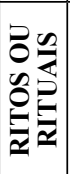 & $\begin{array}{l}\text { São cerimônias com regras de- } \\
\text { termindas que têm como função } \\
\text { transmitir os mitos familiares e } \\
\text { ensinar os membros sobre valo- } \\
\text { res, atitudes e comportamentos. }\end{array}$ & $\begin{array}{l}\text { - Servem para transmitir os mitos; } \\
\text { - Têm uma função de aprendizagem; } \\
\text { - Assinalam as transições do ciclo evolu- } \\
\text { tivo vital da família. }\end{array}$ & $\begin{array}{l}\text { Imber-Black, Ro- } \\
\text { berts \& Whiting } \\
\quad(1991) ; \\
\text { Bennett, Wolin \& } \\
\text { Mcavity (1988) }\end{array}$ \\
\hline 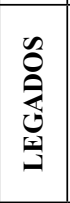 & $\begin{array}{l}\text { Fenômenos que revelam às ge- } \\
\text { rações seguintes os principais } \\
\text { aspectos da família atual e o que } \\
\text { se espera que tenha continuidade. }\end{array}$ & $\begin{array}{l}\text { - Dois passos: } \\
\text { 1) Clarificação/Destilação; } \\
\text { 2) Transmissão. } \\
\text { • Incluem instruções com relação à ma- } \\
\text { neira como deve constituir-se a família } \\
\text { da geração seguinte. }\end{array}$ & $\begin{array}{l}\text { Steinglass et al. } \\
\text { (1989) }\end{array}$ \\
\hline
\end{tabular}

Fonte: adaptado de Falcke \& Wagner (2005). 
Fica claro, assim, que os componentes apresentados no Quadro 1 resumem brevemente os fenômenos cotidianos ocorridos no âmbito familiar, sendo de fundamental importância para a construção da estrutura da instituição famíla, seja essa classificada de qualquer uma das formas descritas na seção anterior.

\section{Considerações finais}

Este estudo se torna interessante, na medida em que permite observar algumas formações de como se constitui a imagem ou a identidade da instituição família. Nesse sentido, percebe-se que houve muitas mutações no que tange a essa instituição, a qual veio sendo afetada no decorrer do tempo por vários fatores advindos do crescimento e do desenvolvimento das nações, dos povos ou da sociedade como um todo.

Destarte, buscou-se aprofundar a formação da identidade familiar, atentando aos aspectos que são fundamentais a isso por meio de algumas vertentes da psicologia, da sociologia e da antropologia. Entretanto, utilizou-se a visão de Falcke \& Wagner (2005) como norteadora deste estudo, visto que as autoras realizaram uma pesquisa prévia para explicar os eventos formadores da cultura familiar como meio de repassar os legados existentes entre as gerações familiares, criando, a partir disso, o termo fenômenos transgeracionais. Esse achado traz uma contribuição importante para a busca do entendimento dos aspectos familiares e vai ao encontro das concepções de base explicativa para a formação da identidade e da imagem da instituição família.

Torna-se importante salientar que, apesar de todas as transformações ocorridas na instituição família, a qual passou de uma estrutura patriarcal para outras estruturas, como visto anteriormente, ainda existem estudos que levam em consideração o modelo tradicional e que contemplam as empresas familiares, como, por exemplo, o estudo de Gersick \& Davis (2006). Nesse sentido, uma crítica que pode ser realizada concerne a um aprofundamento nas vertentes das estruturas ou dos arranjos familiares, os quais guiam os valores e outros fenômenos que formam a construção da identidade e da cultura familiar.

Ressalta-se que esta pesquisa buscou trazer à tona alguns elementos essenciais para qualquer investigação que tenha como foco e objeto de estudo as empresas familiares, pois, para adentrar nesse tipo de organização, é necessário compreender quais são os elementos e fenômenos que formam o seu pano de fundo, o que facilita um entendimento maior por parte do investigador sobre esses aspectos e permite, assim, contribuições mais aprofundadas, tanto para o objeto investigado quanto para o quadro científico ora criado. Trata-se, ainda, de uma investigação prévia e representativa da instituição família, em que, por meio de aspectos epistemológicos, buscou-se proporcionar um entendimento maior desse tipo de instituição, que acaba por afetar outras instituições, tais como as empresas familiares.

Por fim, cabe mencionar a principal limitação deste estudo, que consiste na breviedade com que foi elaborado, visto que se trata de uma construção prévia e, portanto, reduzida de uma temática que precisa ser mais bem discutida em termos epistemológicos. Nesse sentido, sugere-se para investigações futuras ampliar as discussões sobre os fenômenos que interferem na instituição família e sobre a forma como esses fenômenos ocorrem em um ambiente empresarial familiar.

\section{Referências}

ANDOLFI, Maurizio; ANGELO, C. Tempo e mito em terapia familiar. Tempo e mito em terapia familiar, 1989.

BANFIELD, Edward C. The moral basis ofa backward society. New York: 
Glencol, v. 3, p. 4, 1958.

BENNETT, Linda A .; WOLIN, Steven $\mathrm{J}$.; MCAVITY, identidade Katherine J. família, ritual e mito: uma perspectiva cultural nas transições de ciclo de vida. As transições familiares: continuidade e mudança ao longo do ciclo devida, p. 211-234, 1988.

BOSZORMENYI-NAGY, I.; SPARK, G. M. Lealtades invisibles, Amorrortu, Ed. Buenos Aires. Tptulo original: InvisMe loyalties reciprocity in intergenerational family tlierapy. 1973.

BROWN, Reva Berman; MCCARTNEY, Sean. A home from home: the organization as family. Studies in Cultures, Organizations and Societies, v. 2, n. 2, p. 241-255, 1996.

CARPENTER, John; TREACHER, Andy. Problemas y soluciones en terapia familiar y de pareja. Barcelona: Paidós, 1993.

CASEY, Catherine. "Come, join our family": Discipline and integration in corporate organizational culture. Human Relations, 1999, 52.1: 155-178.

CASTELLS, Manuel. O poder da identidade.; Tradução Klauss Brandini Gerhardt. São Paulo: paz e terra, 1999.

DALLOS, Rudi. Sistemas de creencias familiares: Terapia y cambio. Editorial Paidós, 1996.

DAVEL, Eduardo; COLBARI, Antônia. Organizações familiares por uma Introdução a sua tradição contemporaneidade e muldisciplinaridade. Organizações \& Sociedade, v. 7, n. 18, p. 45-64, 2000.

DAVEL, E. Dinâmica sócio-cultural de organizações familiares. Québec, Canadá: Télé-université, Université du Québec, 2003. [Conjunto de textos reunidos].

DAVEL, E.; DANTAS, M. Pluralistic family notions in organizations: organizing and ethnicity in cultural organizations. 20th EGOS Colloquium, Slove- nia, July, 1st - 3rd, 2004.

DE OLIVEIRA CERVENY, Ceneide Maria; BERTHOUD, Cristiana Mercadante Esper. Família e ciclo vital: nossa realidade em pesquisa. Casa do Psicólogo, 1997.

DE SOCIOLOGIA, DICIONÁRIO. Vocabulário Técnico e crítico. Porto Alegre, Globo, 1967.

DIAS, Ana Cristina Garcia; LOPES, Rita de CS. Representações de maternidade de mães jovens e suas mães. Psicologia em estudo, v. 8, p. 63-73, 2003.

FALCKE, Denise; WAGNER, Adriana. A dinâmica familiar e o fenômeno da transgeracionalidade: definição de conceitos. Como se perpetua a família, $p$. 25-46, 2005.

FERREIRA, A. J.. Mitos familiares, interación familiar. Buenos Aires: Tiempo Contemporáneo, 1963.

FONSECA, Cláudia. Olhares antropológicos sobre a família contemporânea. Pesquisando a família: Olhares contemporâneos, p. 55-68, 2004.

FREIRE, Gilberto. Casa Grande \& Senzala: formação da família brasileira sob o regime da economia patriarcal. 21a. ed. Rio de Janeiro: José Olympio, p.387, 1981.

GABRIEL, Yiannis. Beyond happy families: A critical reevaluation of the control-resistance-identity triangle. Human Relations, v. 52, n. 2, p. 179-203, 1999.

GERSICK, K. E.; DAVIS, J. A.; HAMPTON, M. M.; Lansberg. De geração para geração. Rio de Janeiro: Elsevier, 2006.

GOMES, Isabel Cristina; PAIVA, M. L. S. C. Casamento e família no século XXI: possibilidade de holding. Psicologia em Estudo, v. 8, n. 3, p. 9, 2003.

GUBRIUM, Jaber F.; HOLSTEIN, James A. What is family?. Mayfield, 1990. 
HOLSTEIN, James A.; GUBRIUM, Jaber F. Constructing family: Descriptive practice and domestic order. 1994.

IMBER-BLACK, Evan. Os segredos na família e na terapia familiar. Artes Médicas, 1994.

KONDO, Dorinne K. Crafting selves: Power, gender, and discourses of identity in a Japanese workplace. University of Chicago Press, 2009.

MIERMONT, Jacques. Dicionário de terapias familiares: teoria e prática. Artes Médicas, 1994.

PACCOLA, Marilene Krom. Leitura e diferenciação do mito: histórias familiares de adolescentes com problemas. São Paulo: Summus, 1994.

PAGÈS, M., BONETTI, M., GAULEJAC, V. DE, \& DESCENDRE, D.. L'emprise de l'organisation. Presses Universitaires de France, Paris, 1979.

PINCUS, L.; DARE, C. Psicodinâmica da família. Porto Alegre: Artes Médicas, 1981.

PRADO, L. C.; PRADO, L. C. Metáforas, segredos e mitos ao longo do ciclo vital: uma reflexão clínica. Famílias e terapeutas: construindo caminhos, $p$. 199-212, 1996.

RIOS GONZÁLEZ, José A. Manual de orientación y terapia familiar. Madrid: Instituto de Ciencias del Hombre, 1994.

SAWAIA, Bader B. Por que investigo afetividade. Texto apresentado para concurso de promoção na carreira para categoria de Professor Titular do Departamento de Sociologia da PUCSP. São Paulo: PUC/SP, 2000.

STEINGLASS, Peter. La familia alcohólica. Gedisa, 1989.

TODD, Emmanuel. The explanation of ideology: Family structures and social systems. Oxford: Blackwell, 1985.
VÁZQUEZ, Adolfo S. Ética. 21 a edição. Rio de Janeiro: Civilização Brasileira, 2001.

VELHO, Gilberto. Família e subjetividade. Pensando a família no Brasil. Rio de Janeiro: Espaço e Tempo/ UFRRJ, p. 79-87, 1987. 